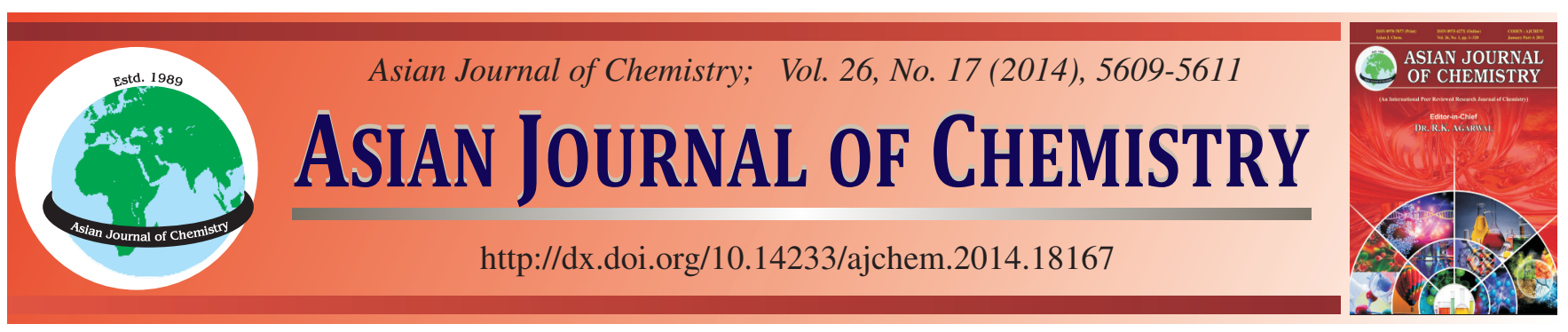

\title{
Study on Fiber Reinforced Polymer Reinforced Circle Column Subjected to Axial Compression $\dagger$
}

\author{
Min Hou, Jiangfeng Dong, Lang Li, Shucheng Yuan and Qingyuan Wang*
}

Key Lab of Energy Engineering Safety \& Disaster Mechanics, Ministry of Education, Sichuan University, Chengdu, P.R. China

*Corresponding author: Tel: +86 13541236416; E-mail: 173847109@qq.com

In order to further advance knowledge of recycled aggregate concrete, fifteen short basalt fiber recycled aggregate concrete columns were fabricated and then tested to investigate the effects of the load carrying capacity, deformability and stiffness of basalt fiber recycled aggregate concrete columns reinforced by carbon fiber reinforced polymer (CFRP) sheets. The results demonstrated that the short columns' ultimate load carrying capacity and stiffness could be greatly increased by two reinforcing arrangements: full wrapping arrangement and partial wrapping arrangement. The results also showed that the greater the carbon fiber reinforced polymer reinforcing ratio, the higher the ultimate load carrying capacity and deformability. In addition, the stiffness of the strengthened basalt fiber columns is more significantly enhanced in the columns that have a full wrapping arrangement than those with only a partial wrapping. Finally, the results indicated that the number of carbon fiber reinforced polymer significantly influences the load carrying capacity of the steel basalt fiber recycled aggregate concrete columns.

Keywords: Carbon fiber reinforced polymer, Basalt fiber, Recycled aggregate concrete columns, Mechanical property.

ᄂ - - - - - - - - - - - - - - - - - - - - - - - - - - - - - - -

\section{INTRODUCTION}

In order to treat and reuse the construction waste reasonably and effectively, scholars have extensively researched the basic properties and applications of recycled aggregate concrete (RAC). In recent years, however, there has been a demand for increasingly high performance requirements for concrete work. The high performance demand then influenced the development and research of fiber-reinforced concrete ${ }^{1,2}$. Basalt fiber is an environmental friendly material that has good chemical performance, thermal stability, a non-toxicity property $^{3}$, is flame resistance ${ }^{4,5}$ and has an acid-base resistance property ${ }^{6}$. Due to recycled aggregate concrete's natural defects, the mechanical properties of the basalt-enhanced recycled concrete were significantly lower than ordinary basaltreinforced concrete, but an external reinforcement can improve both its bearing capacity and deformation capacity. For such reinforcements, fiber-reinforced polymer is widely used, especially the carbon fiber-reinforced polymer (CFRP) ${ }^{7}$. By using this material, the structure's ultimate bearing capacity and plasticity are enhanced and a crack within the concrete's limits is induced by extension. Therefore, the structure is reinforced ${ }^{8}$.

\section{EXPERIMENTAL}

Fifteen pieces of basalt fiber recycled concrete column specimen were designed (size: $100 \mathrm{~mm} \times 100 \mathrm{~mm} \times 400 \mathrm{~mm}$ ). 5 square column specimens were poured at three separate recycled aggregate rates: 0,50 and $100 \%$. Table- 1 details the specimen numbers and their associated parameters. The reinforcement of concrete columns of basalt fiber was completed by using two kinds of reinforcement, by pasting 1 or 2 layers of carbon fiber and by leaving a $1 / 2$ perimeter anchorage length at the truncation in order to ensure the adhesive strength. Taking into account the saving of fiber cloths in engineering applications, fabric reinforced specimen are enforced in only two different forms: either complete reinforcement or no reinforcement.

\section{RESULTS AND DISCUSSION}

Test phenomenon and failure mode: Initially, the deformation of the control short column specimens NC-1, RC50-1 and RC100-1 is linear with the loading. When the load is increased from 70 to $80 \%$ of the ultimate load, the specimen deformation significantly accelerates. Initially, the 


\begin{tabular}{|c|c|c|c|c|c|c|c|c|}
\hline \multicolumn{9}{|c|}{$\begin{array}{c}\text { TABLE-1 } \\
\text { TEST RESULTS }\end{array}$} \\
\hline Specimen & NC-1 & NC-2 & NC-3 & NC-4 & NC-5 & RC50-1 & RC50-2 & RC50-3 \\
\hline$A_{f}(\%)$ & 0 & 75 & 75 & 100 & 100 & 0 & 75 & 75 \\
\hline Reinforcement layers & 0 & 1 & 2 & 1 & 2 & 0 & 1 & 2 \\
\hline Ultimate load $\mathrm{Nu} / \mathrm{kN}$ & 219 & 267.8 & 311.4 & 349 & 356 & 283.56 & 298.4 & 330 \\
\hline Specimen & RC50-4 & RC50-5 & RC100-1 & RC100-2 & $\mathrm{RC} 100-3$ & RC100-4 & RC100-5 & - \\
\hline $\mathrm{A}_{\mathrm{f}}(\%)$ & 100 & 100 & 0 & 75 & 75 & 100 & 100 & - \\
\hline Reinforcement layers & 1 & 2 & 0 & 1 & 2 & 1 & 2 & - \\
\hline Ultimate load $\mathrm{Nu} / \mathrm{kN}$ & 324.8 & 340 & 298 & 298.4 & 354 & 346.2 & 384.8 & - \\
\hline
\end{tabular}

sound of assembly glue peeling can be heard; then, obvious cracks are observed in both the upper and lower parts and the concrete is partly stripped off. Next, the cracks in the upper and lower parts develop into crashing damage and the test is terminated. The deformation of others specimens are not very different from the control column in the elastic stage, but when it is destroyed, the general fiber cloth is pulled off while the concrete is crushed. In RC100-2,RC50-5 and RC100-4, the upper or lower concrete section is crushed and the CFRP pulls off. For remaining specimens, their cores are subjected to shear failure and the CFRP pulls off.

Load analysis: The specimens' bearing capacities are shown in Table-1. From this table, it is evident that after carbon fiber reinforcement, the ultimate bearing capacity of the basalt fiber concrete column has been obviously improved. After the destruction of the core concrete, the restraints of the outsourcing CFRP effectively limits the deformation of the specimen so that the stiffness and ultimate bearing capacity of the reinforced specimen have significantly improved. The lateral constraint of CFRP makes recycled concrete in a three-way force state. Thus, the ultimate load can be improved. The carrying capacity increases together with the reinforcement area. However, the degree of improvement is not proportional to the reinforcement area. Furthermore, the degree of improvement is also not proportional to the reinforcement layers. From these results, it can be concluded that the increase in the bearing capacity of $100 \%$ recycled aggregate concrete is influenced to a degree by different enforcements. Due to the presence of a weak position, no shearing failure occured and its bearing capacity was also greatly affected. The concrete's shear failure caused the destruction of other specimens.

Load-displacement curve: As exhibited in Fig. 1, the specimen's load-displacement curve is divided into the elastic rise and the plastic stage. Compared with the control specimens, the vertical deformations of all the reinforced specimen under the same loads were generally lower, which clearly demonstrates that being strengthened by carbon fiber cloth can effectively improve the stiffness of reinforced specimens. As the load increases, there are significantly less vertical deformations in the reinforcement specimen than in the control specimen, indicating that the fiber cloth has obvious constraints in the circumferential upward. When approaching the ultimate bearing capacity, the carbon fiber is broken and the concrete crushes at the same time, so the specimen is damaged. These results reveal that various reinforcements more greatly impact the reinforced specimen's peak value. Completely reinforced specimens adequately bond with the concrete's outer surface and integrally formed with the concrete, giving the maximum peak for a reinforced specimen. For partly-reinforced specimens, the weak position of the unreinforced area is obvious crushed by concrete and peeled after loading. Therefore, its peak value is slightly smaller than for the reinforced specimen. The CPRF reinforcement layers have a notable, positive effect on the stiffness and ultimate bearing capacity.

Load-strain curve: As seen in Fig. 2a, as the load increased, the circumferential strain of the completely reinforced specimen significantly decreased; incomplete reinforcement also enabled a decrease in circumferential strain, but the magnitude is not as good as for completely reinforcement. The CPRF reinforcement layers have a greater impact on the circumferential strain than the native concrete columns. For instance, the specimen's circumferential strain significantly reduced as CPRF reinforcement layers increased. For the unreinforced recycled and the non-completely reinforced concrete columns, as the recycled aggregate replacement rate increases, the circumferential strain exhibits a certain degree of decrease.

As seen from Fig. 2b, as the load increases, the concrete short columns'axial strain was reduced as the number of CPRF reinforcement layers increased. Additionally, the impact on the completely enforced columns was more obvious. The axial
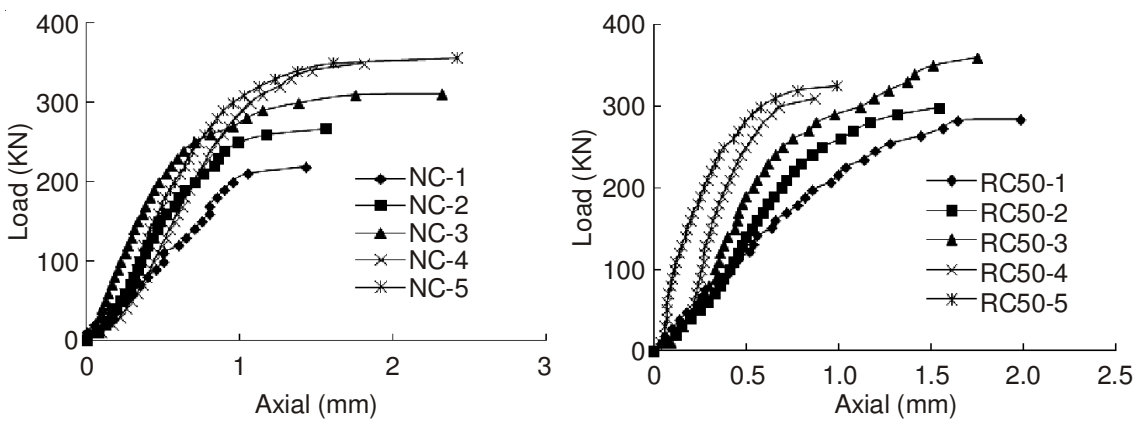

Fig. 1. Load-axial displacement curves

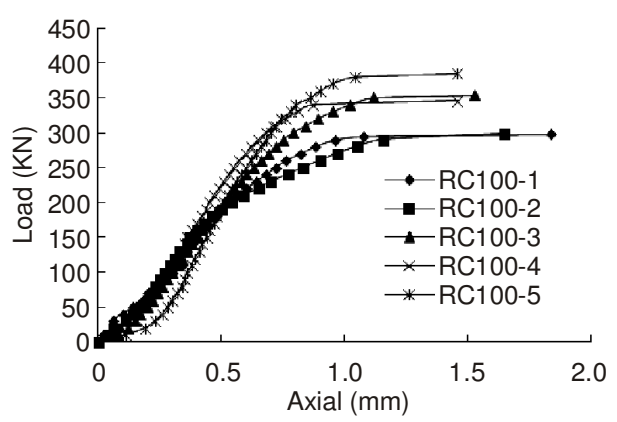



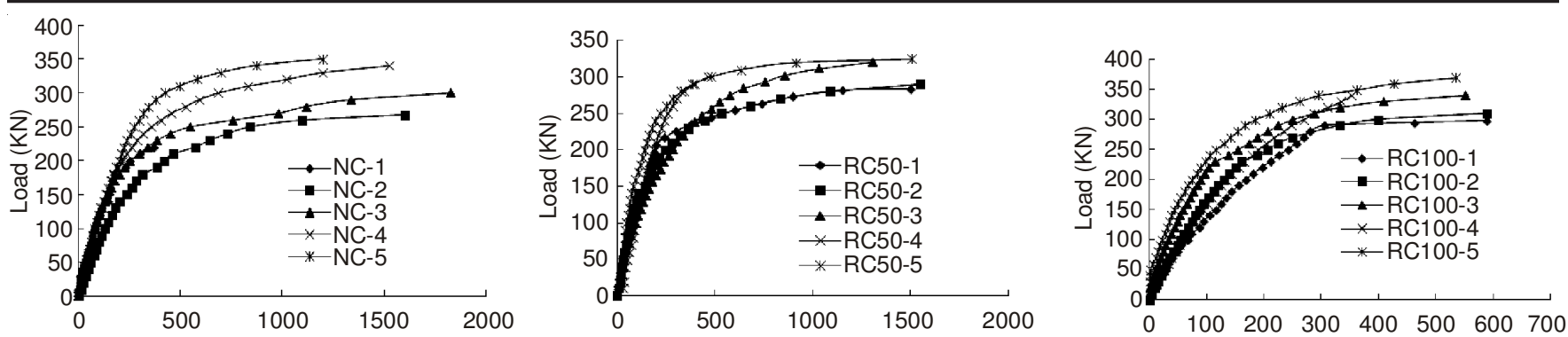

(a) Load-circumferential strain
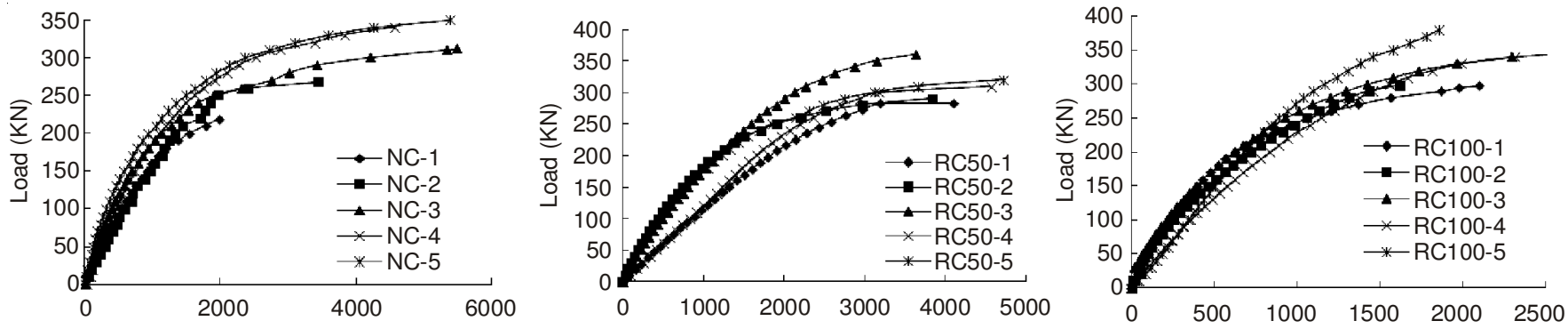

(b) Load-axial strain

Fig. 2. Load-strain curves

strain of the unreinforced and non-completely reinforced recycled concrete short columns decreased as the recycled aggregate replacement rate increased. After the completely reinforced columns, the recycled concrete square columns' axial strain increased with the recycled aggregate rate. However, when the recycled aggregate replacement rate reached $50 \%$, the specimen's axial strain decreased as the recycled aggregate rate increased. Additionally, recycled concrete column is much better improved than the native concrete columns.

\section{Conclusion}

- The test results clearly demonstrate that the externally bonded carbon fiber cloth can improve the bearing capacity of fiber recycled concrete specimens; furthermore, this is a very effective reinforcement method.

- The larger the carbon fiber cloth area, the more obvious improved the reinforced specimen's ultimate bearing capacity. The CFRP reinforced layers also greatly impact the specimen's ultimate bearing capacity.

- After being strengthened, the specimen's overall stiffness and deformation capacity have improved. Furthermore, the ultimate strength and stiffness of the all-inclusive reinforcement specimen improves more than the half-inclusive reinforced specimens.
- As can be seen from the circumferential and axial strain, CFRP reinforcement can significantly increase the concrete's stiffness and to some degree enhances both the elastic stage and plastic stage.

\section{ACKNOWLEDGEMENTS}

The authors acknowledged the Lab of Energy Engineering Safety \& Disaster Mechanics, Ministry of Education for fund. The authors also thank Mr. Shi-lei Yuan and Miss Wei Liang for their assistance.

\section{REFERENCES}

1. D.P. Dias and C. Thaumaturgo, Cement Concr. Compos., 27, 49 (2005).

2. J. Sim, C. Park and D.Y. Moon, Composites Part B, 36, 504 (2005).

3. V. Fiore, G. Di Bella and A. Valenza, Mater. Des., 32, 2091 (2011).

4. B. Wei, H. Cao and S. Song, Mater. Sci. Eng. A, 527, 4708 (2010).

5. B. Wei, H. Cao and S. Song, Mater. Des., 31, 4244 (2010).

6. M. Berozashvili, Adv. Mater. Composites News, 6, 5 (2001).

7. G. Kim, J. Sim and H. Oh, Construct. Build. Mater, 22, 1261 (2008).

8. T.K. Lee and R. Al-Mahaidi, Compos. Struct., 82, 185 (2008). 